\title{
Analysis on improving strategy of lithium thionyl chloride battery used for landmine fuze based on SWOT-AHP method
}

\author{
Xiao Wang ${ }^{1}$, Xin Wang ${ }^{1}$, Nan Zhang ${ }^{1, *}$, and Tengran Niu ${ }^{1}$ \\ ${ }^{1}$ Traning basement of Army engineering university of PLA, 221000 Xuzhou Jiangsu Province, China
}

\begin{abstract}
As the landmine is now always detonated by electronic fuzes which are usually powered by the battery inside landmines. As a weapon, landmines are required to be reliable during long service time and the performance of the battery is essential to the operation effectiveness of the landmines. This paper analyzes qualitatively the main factors which have effects on the improving strategic choice of lithium thionyl chloride battery which is used for fuzes of certain landmine weapon to power up based on SWOT-AHP method. The strengths, weaknesses, opportunities and threats of the battery are analyzed and the weights of each factor are calculated and sorted by analytic hierarchy process (AHP) method. The result shows that the SO development strategy should be taken. The study provides direct and feasible improving method of landmine fuzes use lithium thionyl chloride battery.
\end{abstract}

\section{INTRODUCTION}

China as being a signatory of amended Protocol on Prohibitions or Restrictions on the Use of Mines, BoobyTraps and Other Devices, at present the mines used by the PLA are equipped with Self-destruction and Selfdeactivating functions. The electronic fuses are always powered by the battery inside mines which is essential to the operation of the munition. The electronic Fuses requires the battery with small volume, light weight, wide range of working temperatures and long storage life to adapt to the application of different geographical areas.

Lithium thionyl chloride battery, which also called " Disposable battery" or "primary lithium battery" because it cannot be reused, is most common to supply the electronic fuses of mines due to the characteristics of high working voltage, high specific energy, long storage life and low self-discharge rate. However, when the battery discharging with high current after long-term storage or service, the voltage of the battery decreases rapidly and then increases back to normal slowly which called voltage delay. During this period, the failure of battery such as discharge capacity, impedance and safety performance may happen. The service years of mine usually ranges from 8 to 10 years. ${ }^{[1]}$ Due to the requirements of sealing, waterproof and resistance to ECM of mines, the battery installed in mines generally designs as unchangeable. If the reliability of Li battery decreases, the failure of battery can lead to the safety risk. Considering of operational effectiveness on mines, the causes of failure on battery need to be evaluated and figure out the main characters. It is conducive to further optimize the performance of battery objectively and achieve the balance of battlefield use, operational effectiveness and production cost.

\section{Research method}

\subsection{Literature analysis}

Searching relevant information about improving Lithium thionyl chloride battery serves as a theoretical underpinning.

\subsection{Expert interviews and questionnaire method}

Consulting the experts or distributing and collecting questionnaires to acquire the opinion of the experts.

\subsection{SWOT-AHP model}

Based on the research and Combined with the consulting and questionnaire of experts, the SWOT-AHP model is built. The SWOT-AHP model is a combination of quantitative and qualitative. Analytic Hierarchy Process is raised by professor T. L. Satty, an expert in operations research of United States. AHP can quantize the complex problem based on arithmetic logic and come out with proper decision-making method. ${ }^{[2]}$

\subsubsection{Establishing the SWOT-AHP model}

Through literature analysis on the relevant information, the factors which have influence on Lithium thionyl chloride battery of certain landmine have been ordered in permutation into S for Strengths, W for Weaknesses, O for Opportunities and T for Threats. And based on SWOT, the factors are divided into different levels to form a multilevel analytical structure of AHP model objectively.

\footnotetext{
*Corresponding author: kelsi03@163.com
} 


\subsubsection{Establishing the judgment matrix}

To evaluate the performance of the Lithium thionyl chloride battery, the failure factor which affecting the operation effectiveness of the landmines must be determined and distinguish the relationship between major and minor factors. Whether the selection of evaluation parameters is complete or not, whether main parameters are accurate or not, and whether the influence levels of parameters are correct or not are directly related to the accuracy and authenticity of the evaluation result. Depending on consulting and questionnaire of experts, according to the proportion from 1 to 9 to measure the weights of effecting factors of each Level, Comparing the factors from each level in pairs, according to the scaling theory, the comparison scale of relative importance can be acquired to form the five judge matrix of $\mathrm{A}, \mathrm{S}, \mathrm{W}, \mathrm{O}, \mathrm{T}^{[3]}$

\subsection{3 hierarchical ranking and consistency check}

Depending on the hierarchical ranking and consistency check to determine the influence of different factor from different level towards object level.

\subsubsection{Selecting the Optimal improvement scheme}

Forming the SWOT Quadrilateral by the ranking weights of different level which are the highest weights of S, W, O and T. After calculating the coordinate of center of gravity, the corresponding strategy type can be obtained.

\section{SWOT analysis of lithium thionyl chloride battery for certain landmine}

\subsection{Strengths of lithium thionyl chloride battery for certain landmine}

\subsubsection{High specific energy}

The specific energy of lithium thionyl chloride battery is the highest among all Disposable batteries at present which reaches $650 \mathrm{wh} / \mathrm{kg}$ and $1280 \mathrm{wh} / \mathrm{dm}^{3}$ at low discharge rate. It can also discharge at $10 \mathrm{~mA} / \mathrm{cm}^{2}$ or higher current density which is twice as much as a normal battery. This means the battery can be small and less weight which is perfect for landmine fuze usage considering the volume of landmine.

\subsubsection{High working voltage}

The open circuit voltage of the battery is $3.65 \mathrm{~V}$, when discharging at $1 \mathrm{~mA} / \mathrm{cm}^{2}$, the voltage can be maintained at $3.3 \mathrm{~V}$. And the voltage remains unchanged within $90 \%$ of the battery capacity.

\subsubsection{Good performance at both high and low temperature}

As we all know that China has vast territory. China's territory starts from the Mohe River in the north, reaches the the Nansha Islands in the south, the confluence of the Heilongjiang River and the Wusuli River is in the most east area, and the Pamir Plateau in the west. China has complex national boundaries and many neighboring countries. Landmine is always used to safeguard our country's territorial integrity. Within in China, the temperature can range from far below $0{ }^{\circ} \mathrm{C}$ to more than $40{ }^{\circ} \mathrm{C}$. And the battery can work normally at $-40-50{ }^{\circ} \mathrm{C}$ and the capacity at $-40{ }^{\circ} \mathrm{C}$ is about $50 \%$ of that at room temperature.

\subsubsection{Good storage performance}

For the landmine weapon, the battery and fuze are packaged as a whole. Generally, the Lithium thionyl chloride battery can be shelved for 5 years or longer.

\subsection{Weaknesses of lithium thionyl chloride battery for certain landmine}

\subsubsection{Capacity fade}

Percentage of the amount of power a battery will lose per month even without a current load. A slow chemical reaction takes place inside the battery which continuously reducing the battery's power. As the self-discharge happening during storage, the capacity of the battery will drop about $5 \%$ per year. When designing the fuze, the selection of the battery capacity always is four times more than what really needs.

\subsubsection{Voltage hysteresis}

After long-term storage or operation at room temperature, the working voltage of Lithium thionyl chloride battery will drop sharply and return to normal slowly when it is discharged with high current. In order to reduce selfdischarge of the battery, a protective film is formed from lithium and electrolyte which is called passivating film. With the increase of ambient temperature and storage time, the passivating film gradually expands and becomes thicker which has effect on the migration speed of lithium ions. When the current is high, a large voltage drop occurs at both ends of the passivating film, and the battery shows a low load voltage.

\subsubsection{Thermal runaway}

If the battery is stored in the discharge state, it may explode at high temperature due to uncontrolled heat.

\subsection{Opportunities of lithium thionyl chloride battery for certain landmine}

\subsubsection{Increasing scientific research fund}

In recent years, increasing attention has been paid in research and development funds, and technology has been 
improved with good research environment.

\subsubsection{Enhanced processing technology}

China is vigorously developing the ability of independent innovation and practicing the scientific concept of development. Due to the reasons of policies and market benefits, the construction of independent innovation ability in the process has achieved certain results. Only by strengthening our own ability of process innovation can we achieve sustainable and rapid development.

\subsubsection{Development of new materials}

During the storage of battery, the impurities in the material will lead to serious voltage hysteresis, aggravation of self discharge and increasing of failure rate. For the power battery, due to the large reaction area, the influence of material is more prominent. As the new materials developing continuously, this situation can be improved gradually.

\subsection{Threats of lithium thionyl chloride battery for certain landmine}

\subsection{1 processing technology}

The low degree of automation and processing technology of domestic equipment led to the poor product consistency which has negative influence on the performance of the battery

\subsubsection{Impurities in the material}

The domestic raw materials, such as glass fiber separator, lithium belt, carbon and so on, have higher internal impurity content compared with foreign products. The material is not pure or not well protected, causing material pollution which have effect on the performance of Lithium thionyl chloride battery.

\subsubsection{A gap with the most advanced international level}

Compared with foreign countries such as Israel which belongs to the world-class level in production of lithium battery, the performance of the lithium thionyl chloride battery is differed from voltage hysteresis and increasing self-discharging. The battery made by Israel is much better on the performance after long time storage or service time and it still in good condition.

\section{4 ahp analysis of lithium thionyl chloride battery for certain landmine}

\subsection{AHP model of lithium thionyl chloride battery for certain landmine}

Based on the SWOT analysis of lithium thionyl chloride battery for certain landmine, all the factors of $\mathrm{S}, \mathrm{W}, \mathrm{O}$ and $\mathrm{T}$ groups are divided into different levels to form a multilevel analytical structure objectively as shown in the Figure 1.

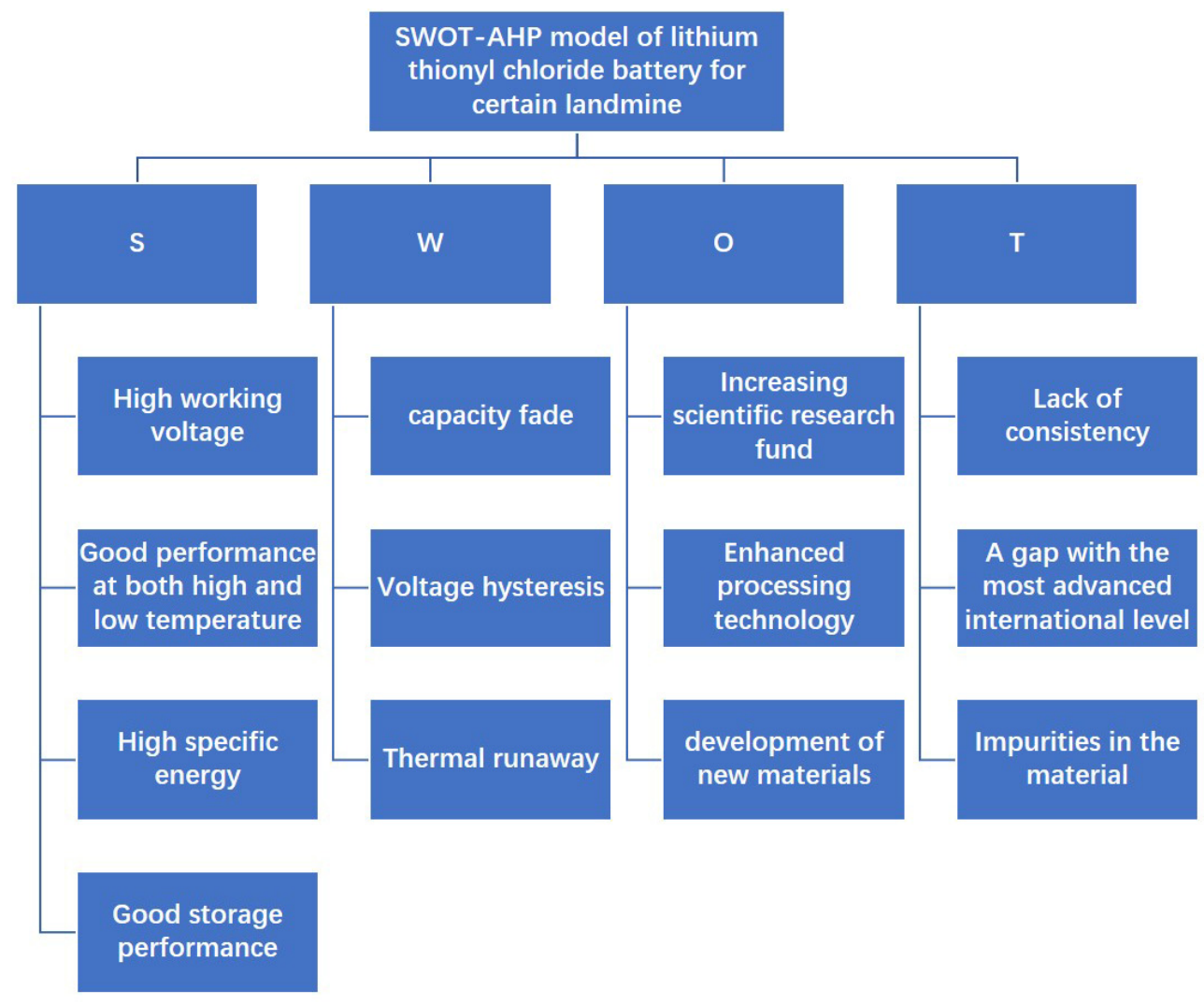

Fig. 1. AHP model of lithium thionyl chloride battery for certain landmine. 


\subsection{AHP hierarchical ranking and consistency check of lithium thionyl chloride battery for certain landmine}

Depending on the model of SWOT-AHP model, comparing the factors from each groups in pairs and according to the scaling theory, the judge matrix of $\mathrm{A}, \mathrm{S}$, $\mathrm{W}, \mathrm{O}, \mathrm{T}$ can be achieved. The consistency can be calculated and if it is less than 0.1 , meaning the consistency check is satisfied. The result is shown in Table 1. The factors that have most effect on the battery is the opportunity of Enhanced processing technology, strength of high working voltage and threat of Impurities in the material. All in all, it means the battery has unique advantage for landmine fuze usage and the development of the processing technology can promote the improvement of the battery. However, the threat should not be ignored especially the impurities in the materials affects the performance of the battery which is also bad for the operational effectiveness of landmine weapon.

Table 1. AHP hierarchical ranking and consistency check.

\begin{tabular}{|c|c|c|c|c|c|c|}
\hline SWOT & C.R & $\begin{array}{l}\text { PRIORITY } \\
\text { OF EACH } \\
\text { GROUP }\end{array}$ & FACTORS & C.R & $\begin{array}{l}\text { PRIORITY } \\
\text { OF EACH } \\
\text { FACTOR }\end{array}$ & $\begin{array}{l}\text { PRIORITY } \\
\text { OF ALL }\end{array}$ \\
\hline \multirow{4}{*}{ S } & \multirow{13}{*}{$\begin{array}{c}0.0736 \\
<0.1\end{array}$} & \multirow{4}{*}{0.3435} & $\begin{array}{l}\text { High working } \\
\text { voltage }\end{array}$ & \multirow{4}{*}{$\begin{array}{c}0.0295 \\
<0.1\end{array}$} & 0.4744 & 0.163 \\
\hline & & & $\begin{array}{l}\text { Good performance } \\
\text { at both high and low } \\
\text { temperature }\end{array}$ & & 0.0692 & 0.0238 \\
\hline & & & High specific energy & & 0.2549 & 0.0876 \\
\hline & & & $\begin{array}{l}\text { Good storage } \\
\text { performance }\end{array}$ & & 0.2016 & 0.0692 \\
\hline \multirow{3}{*}{ W } & & \multirow{3}{*}{0.3188} & capacity fade & \multirow{3}{*}{$\begin{array}{c}0.0121 \\
<0.1\end{array}$} & 0.1194 & 0.0124 \\
\hline & & & Voltage hysteresis & & 0.7471 & 0.0777 \\
\hline & & & Thermal runaway & & 0.1336 & 0.0139 \\
\hline \multirow{3}{*}{0} & & \multirow{3}{*}{0.2337} & $\begin{array}{l}\text { Increasing scientific } \\
\text { research fund }\end{array}$ & \multirow{3}{*}{$\begin{array}{c}0.0176 \\
<0.1\end{array}$} & 0.122 & 0.0389 \\
\hline & & & $\begin{array}{l}\text { Enhanced } \\
\text { processing } \\
\text { technology }\end{array}$ & & 0.5584 & 0.178 \\
\hline & & & $\begin{array}{c}\text { development of new } \\
\text { materials }\end{array}$ & & 0.3196 & 0.1019 \\
\hline \multirow{3}{*}{ T } & & \multirow{3}{*}{0.104} & Lack of consistency & \multirow{3}{*}{$\begin{array}{c}0.0624 \\
<0.1\end{array}$} & 0.279 & 0.0652 \\
\hline & & & $\begin{array}{l}\text { A gap with the most } \\
\text { advanced } \\
\text { international level }\end{array}$ & & 0.0719 & 0.0168 \\
\hline & & & $\begin{array}{l}\text { Impurities in the } \\
\text { material }\end{array}$ & & 0.6491 & 0.1517 \\
\hline
\end{tabular}

\subsection{Selecting the Optimal improvement scheme of lithium thionyl chloride battery for certain landmine}

According to the quadrant model and quadrilateral rule of SWOT, the most influential weights of S, W, O and T groups are marked on the coordinate axis to construct the quadrilateral shown in Figure 2. Due to the area formed by $\mathrm{S}, \mathrm{W}, \mathrm{O}, \mathrm{T}$ factors and coordinate axis, $S_{S A O}>S_{S A T}>$ $S_{W A O}>S_{W A T}$. The SO strategy should be taken.

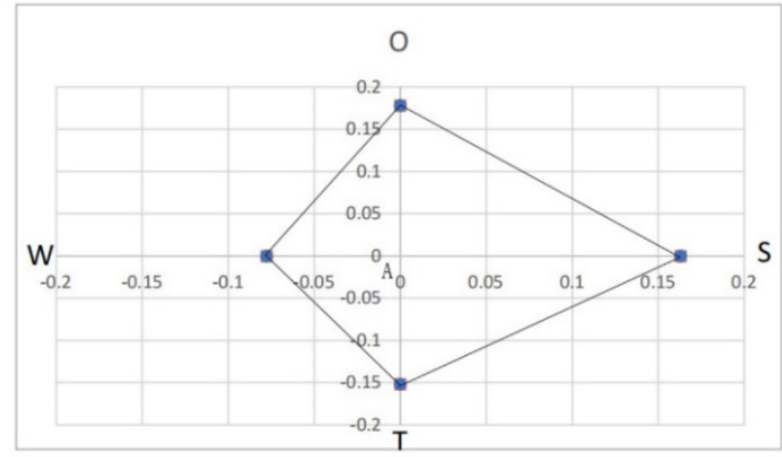

Fig 2. SWOT quadrilateral.

\section{CONCLUSION}

In this paper, the combination of SWOT and AHP is qualitative and quantitative analysis method to choose the most suitable strategy which in this case is the SO strategy. Firstly, as the processing technology has been enhanced, laser welding technology can be used to replace argon arc welding in the sealing welding of battery, which can effectively avoid the occurrence of battery pollution. Secondly, through the advanced laser welding technology, the welding surface can ensure the strength of sealing. Also compared with the import diaphragm, the automatic production process ensures the consistency and reliability of diaphragm quality, and the good monitoring measures can eliminate the weak diaphragm in time, so as to reduce the occurrence of micro short circuit.

\section{References}

1. Dong Zhonghong, Gong Feng, Dai Qiuyue, Yuan Muting. Study on storage performance of long-life lithium primary battery for torpedo. Power technology. 2020, 44(8): 1161-1164

2. Satty T L, HU H. Ranking by the eigenevector versus other methods in the analytic hierarchy process[J]. Applied mathematical letters, 1998(4):121-125.

3. Satty $\mathrm{T}$ L. Analytic Hierarchy Process[M].New York:Mc Graw-Hill International,1980:56-84. 